\title{
Overweight and obesity among public and private primary school children in Nairobi, Kenya
}

\author{
Florence Kyallo ${ }^{1 *}$, Anselimo Makokha ${ }^{1}$, Alice Mboganie Mwangi ${ }^{2}$ \\ ${ }^{1}$ Department of Food Science and Technology, Jomo Kenyatta University of Agriculture and Technology, Juja, Kenya; \\ *Corresponding Author: florencemuthiani@yahoo.com \\ ${ }^{2}$ Department of Food Science, Nutrition and Technology, University of Nairobi, Nairobi, Kenya
}

Received 9 May 2013; revised 15 June 2013; accepted 20 July 2013

Copyright (C) 2013 Florence Kyallo et al. This is an open access article distributed under the Creative Commons Attribution License, which permits unrestricted use, distribution, and reproduction in any medium, provided the original work is properly cited.

\begin{abstract}
Obesity is on the rise in developing countries, especially in urban areas. In this study, a crosssectional study was conducted in two divisions in Nairobi province to determine the prevalence of and some risk factors associated with overweight and obesity among school children in Nairobi, Kenya. It involved 344 school children aged 9 - 14 years drawn from four randomly selected public and private primary schools. Weight and height were measured and body mass index was calculated. Nutrition status was determined using the World Health Organization age and gender specific BMI-for-age Z-scores (BAZ). The chi-square test was used to determine the relationship between overweight/obesity and selected socio-demographic characteristics. Complete anthropometric measurements were available for 321 children. Prevalence of combined overweight and obesity (BAZ > +1SD) was $19.0 \%$, with prevalence being higher among girls $(21.0 \%)$ than boys $(16.9 \%)(p=0.632)$. The prevalence among children in private schools was significantly higher $(29.0 \%)$ than among those in public schools $(11.5 \%)(p=0.000)$. In addition, being a single child $(p=0.020)$, birth order $(p=0.017)$, mother's occupation $(p=0.023)$ and type of residence $(p=0.028)$ were positively associated with overweight/obesity. The prevalence of overweight/obesity determined in this study is high and is a public health concern, with girls particularly at risk of becoming overweight.
\end{abstract}

Keywords: Obesity; Overweight; School Children;

"Conflict of interest: The authors declare that there is no conflict of interest.

\section{Kenya}

\section{INTRODUCTION}

In Sub-Saharan Africa, most nutrition efforts have concentrated on under-nutrition among children, and national surveys hardly report on overweight. However, there is growing evidence that childhood obesity is on the rise worldwide, in both developed and developing countries [1-3]. While previous Kenya Demographic Health Surveys (KDHS) did not report on overweight among children, data available from analyses of these surveys indicated the presence of overweight among preschool children in Kenya [4-6]. In 1993, prevalence of overweight (defined as weight-for-height $>2 \mathrm{SD}$ ) among children 0 - 5 years old was $3.5 \%$ [4], 12.2\% among those 12 - 59 months (defined as weight-for-height $>$ 1SD) [5] and $17.8 \%$ among 3 - 5 years old (defined as BMI-for-age Z score $>+1$ SD) [6]. The 2008-2009 Kenya Demographic Health Survey reported a prevalence of overweight of $1.2 \%$ among $0-5$ years old (defined as weight-for-age $>$ 2SD) [7]. While the use of different definitions makes it difficult to compare the trend of overweight/obesity among pre-school children between 1993 and 2008, there is evidence of rising prevalence among women, (from $13.8 \%$ in 2003 to $23.4 \%$ in 2008), with the prevalence in urban areas reported at $39 \%[7,8]$. Given that parental obesity is one of the most potent risk factors for obesity [9], this trend may indicate increasing rates among school going children in the country as well. Hence, the objective of this study was to determine the prevalence of overweight and obesity among children attending public and private primary schools in Nairobi.

\section{METHODOLOGY}

A cross-sectional study was conducted in two divisions in Nairobi province between September and No- 
vember 2008. School going children aged 9 - 14 years (classes 5 and 6) and attending public or private primary schools in Nairobi formed the study population. Nairobi is the capital city of Kenya and the children come from different socio-economic status, with poverty and opulence occurring almost in the same neighborhoods. Generally those from low socio-economic background attend predominantly public schools while a high proportion of those from well off backgrounds attend private schools. Residents of Nairobi have easy access to numerous fast food outlets, restaurants, supermarkets and sedentary recreation facilities, such as access to television, computers and motorized transport.

The schools were randomly selected from two divisions in Nairobi province. The calculated sample size was 364, of which 344 parents gave written consent for their children to participate in the study. Complete anthropometric data was obtained for 321 children.

All measurements were taken in the school compound in privacy. Weight and height measurements were made according to standard procedures [10]. Weight was measured to the nearest 0.1 kilograms using a standard weighing scale with child having minimum clothing. Height was measured to the nearest centimetre with child wearing no shoes. Body Mass Index (BMI) was calculated as $\mathrm{kg} / \mathrm{m}^{2}$. BMI-for-Age Z-scores were calculated using WHO AnthroPlus. Overweight and obesity was determined using the WHO gender specific BMI-for-age Zscores (BAZ) for children 5 - 19 years [11]. Underweight was defined as $\mathrm{BAZ} \leq-2 \mathrm{SD}$, normal as $-2 \mathrm{SD}<\mathrm{BAZ} \leq$ $+1 \mathrm{SD}$, overweight as $+1 \mathrm{SD}<\mathrm{BAZ} \leq+2 \mathrm{SD}$, obese as BAZ $>+2 \mathrm{SD}$ and overweight/obesity as BAZ $>+1 \mathrm{SD}$.

Data was analysed using SPSS version 17.0 and WHO AnthroPlus. Measures of central tendency and dispersion were determined for quantitative variables (age, weight, height, BMI). Student's t-test was used to test continuous data. Frequency distributions of categorical data (sex, school type, number of siblings, residence, parents' occupation and education levels) were determined and associations between population groups and prevalence rates determined using Chi-square statistics. A p-value of less than 0.05 was considered significant. Risk factors were determined by comparing selected socio-demographic characteristics of normal and overweight/obese children. Underweight children were only eleven and were excluded from this comparison. The study protocol was approved by the National Ethical Review committee, Kenya Medical Research Institute (KEMRI). In addition, the school administrators, parents/guardians of the children gave written consent to participate in the study. Participation was purely voluntary.

\section{RESULTS}

A total of 344 children participated in the study (59.6\% public from schools). About half (52.3\%) of the children were female. The mean age of the children was 12.0 years $(9.8-14.7$ years). There was no significant difference in age between males and females $(t=1.8, d f$ $=342, p=0.08$ ).

As shown in Table 1, girls in public schools, but not in private schools, were significantly heavier and had higher mean BMI ( $p=0.009$ and $p=0.018$, respectively) than boys in the same schools. In private schools, girls were significantly taller than boys $(p=0.018)$, unlike in public schools, where there was no significant difference in height between girls and boys $(p>0.05)$.

Overall, prevalence of overweight/obesity was $19.0 \%$ $(21.0 \%$ and $16.8 \%$ among females and males, respectively $\chi^{2}=0.916, d f=2, p=0.632$ ). Overweight/obesity was significantly higher in private $(29.0 \%)$ than in public $(11.5 \%)$ schools $\left(\chi^{2}=16.9, d f=2, p=0.000\right)$ (Tables 2). While overweight/obesity among boys in private schools $(27.1 \%)$ was three times higher than among boys in public schools $(9.0 \%)\left(\chi^{2}=8.4, d f=1, p=0.004\right)$, girls in private schools were 2.5 times more likely to be overweight/obese $(32.3 \%)$ compared to those in public schools $(14.7 \%)\left(\chi^{2}=7.0, d f=1, p=0.008\right)$. However, within the schools, there were no significant differences in overweight status between boys and girls $(p>0.05)$.

The prevalence of overweight $(+1 \mathrm{SD} \leq \mathrm{BAZ} \geq+2 \mathrm{SD})$ and obesity (BAZ $>+2 \mathrm{SD}$ ) was significantly higher in private schools than in public schools. Overweight in private schools was $18.1 \%$ compared to $9.3 \%$ in public schools $(p=0.032$. At $10.9 \%$, the prevalence of obesity in private schools was significantly higher than that in public schools $(2.2 \%)\left(\chi^{2}=10.7, d f=1, p=0.001\right)$.

Similarly, the prevalence of overweight $(+1 \mathrm{SD}>\mathrm{BAZ}$ $<+2 \mathrm{SD}$ ) among girls in private schools was significantly higher than among girls in public schools $(p=0.02)$. When obesity was considered separately, $10.4 \%$ of the girls in private schools were obese compared to $3.0 \%$ in

Table 1. Mean anthropometric characteristics of study children by sex and school type.

\begin{tabular}{|c|c|c|c|c|c|c|}
\hline & \multicolumn{3}{|c|}{ Private Schools $($ Mean \pm SD) } & \multicolumn{3}{|c|}{ Public Schools (Mean \pm SD) } \\
\hline & Male $n=70$ & Female $n=68$ & p-value & Male $n=84$ & Female $n=99$ & $p$-value \\
\hline Weight (kg) & $40.6(8.80)$ & $43.6(10.69)$ & 0.084 & 36.7 (6.96) & $40.2(9.43)$ & 0.009 \\
\hline Height (cm) & $147.0(0.08)$ & $151.0(0.08)$ & 0.018 & $146.0(0.08)$ & $148.0(0.08)$ & 0.085 \\
\hline $\operatorname{BMI}\left(\mathrm{kg} / \mathrm{m}^{2}\right)$ & $18.6(3.43)$ & $19.2(4.30)$ & 0.757 & $17.1(2.02)$ & $18.2(3.29)$ & 0.018 \\
\hline
\end{tabular}


Table 2. Mean anthropometric characteristics of study children by sex and school type.

\begin{tabular}{ccccccc}
\hline & \multicolumn{2}{c}{ All (\%) } & \multicolumn{2}{c}{ Private school (\%) } & \multicolumn{2}{c}{ Public school (\%) } \\
\cline { 2 - 7 } & Private $(n=138)$ & Public $(n=183)$ & Male $n=70$ & Female $n=68$ & Male $n=84$ & Female $n=99$ \\
\hline Underweight & 2.2 & 5.5 & 0.0 & 4.4 & 7.1 & 4.0 \\
Overweight & $18.1^{\mathrm{a}^{*}}$ & 9.3 & 15.7 & 20.6 & 7.1 & 11.1 \\
Obese & $10.9^{\mathrm{a}^{* *}}$ & 2.2 & 11.4 & 10.3 & 1.2 & 3.0 \\
Overweight/obesity & $29.0^{\mathrm{a}^{* *}}$ & 11.5 & 27.1 & 30.9 & 8.3 & 14.1 \\
\hline
\end{tabular}

${ }^{*} p<0.05 ;{ }^{* *} p<0.01$; underweight, BMI-for-age Z-score (BAZ) $<-2 \mathrm{SD}$; Overweight/obese, BAZ $>+1 \mathrm{SD}$; obese, BMI-for-age Z-score $>+2 \mathrm{SD}$; ${ }^{\mathrm{a}} \mathrm{Significantly}$ higher in private than in public schools.

public schools $(p=0.052)$. However, there were no significant differences in nutrition status between boys in private schools and those in public schools.

On average, the study children had 2 siblings, ranging from none to nine [9] siblings. There was a trend of decreasing prevalence of overweight/obesity with increasing number of siblings $(p=0.058)$ (Table 3). Overweight/obesity was significantly higher among children who had no siblings $(37.0 \%)$ compared with those with at least one sibling $(18.1 \%)(p=0.02)$.

When overweight/obesity was compared according to birth order, there was a significant difference $(p=0.01)$ in overweight/obesity based on the birth order, with the highest prevalence being among those children who had no siblings, followed by last born and first born children. Overweight/obesity among children living with both parents (father and mother) was 1.6 times higher than among children living with one parent, although the difference was not significant $(p=0.128)$.

Mothers' and fathers' level of education did not make a significant difference in rates of overweight/obesity ( $p$ $>0.05$ ) (Table 3). However, the prevalence of overweight/obesity was highest among children whose fathers had university level education, followed by those whose mothers had college and university education.

There was a significant difference in overweight/obesity rates based on the occupation of mothers of the children $\left(\chi^{2}=8.8, d f=3, p=0.03\right)$, but not that of fathers (Table 4). For both parents, the rate was highest among children whose parents were self-employed, and lowest among children of unemployed mothers. When the type of residence was considered, there was a significant difference in overweight/obesity $\left(\chi^{2}=9.1, d f=3, p=0.03\right)$ with overweight/obesity lowest among children who lived in residences with own compounds (13.1\%) and highest among those who lived in residential courts (29.1\%). Prevalence was similar among children who lived in apartment blocks and single rooms.

\section{DISCUSSION}

Comparison of prevalence of overweight and obesity rates among children and adolescents is usually compli-
Table 3. Overweight/obesity by socio-demographic characteristics of the study children.

\begin{tabular}{|c|c|c|c|c|}
\hline $\begin{array}{c}\text { Socio-demographic } \\
\text { factors }\end{array}$ & $\begin{array}{c}\text { Normal } \\
\text { Children }(\%)\end{array}$ & $\begin{array}{c}\text { Overweight/ } \\
\text { obesity } \\
\text { children (\%) }\end{array}$ & $\begin{array}{l}\text { Odds Ratio } \\
(95 \% \mathrm{CI})\end{array}$ & p-value \\
\hline \multicolumn{5}{|c|}{ Type of school } \\
\hline Private & 70.1 & 29.9 & $3.1(1.72-5.58)$ & 0.000 \\
\hline Public & 87.9 & 12.1 & & \\
\hline \multicolumn{5}{|l|}{ Sex } \\
\hline Male & 82.4 & 17.6 & $0.76(0.43-1.34)$ & 0.343 \\
\hline Female & 78.1 & 21.9 & & \\
\hline \multicolumn{5}{|l|}{ Male } \\
\hline Private & 72.9 & 27.1 & $3.78(1.48-9.66)$ & 0.004 \\
\hline Public & 91.0 & 9.0 & & \\
\hline \multicolumn{5}{|l|}{ Female } \\
\hline Private & 67.2 & 32.8 & $2.86(1.32-6.18)$ & 0.006 \\
\hline Public & 85.4 & 14.6 & & \\
\hline \multicolumn{5}{|l|}{ Age } \\
\hline $9-10$ & 75.0 & 25.0 & - & 0.411 \\
\hline $11-12$ & 79.8 & 20.2 & & \\
\hline $13-14$ & 88.9 & 1.1 & & \\
\hline \multicolumn{5}{|c|}{ Having siblings or not } \\
\hline No sibling & 63.0 & 37.0 & $2.65(1.15-6.13)$ & 0.020 \\
\hline$\geq 1$ siblings & 81.9 & 18.1 & & \\
\hline \multicolumn{5}{|c|}{ Number of siblings } \\
\hline$\geq 3$ siblings & 82.9 & 17.1 & - & 0.058 \\
\hline $1-2$ siblings & 81.0 & 19.0 & & \\
\hline No sibling & 63.0 & 37.0 & & \\
\hline \multicolumn{5}{|c|}{ Birth } \\
\hline Only child & 63.0 & 37.0 & - & 0.017 \\
\hline Last born & 74.4 & 25.9 & & \\
\hline First born & 83.3 & 16.5 & & \\
\hline $\begin{array}{l}\text { Other birth } \\
\text { positions }\end{array}$ & 87.0 & 13.2 & & \\
\hline \multicolumn{5}{|c|}{ Parent child lives with } \\
\hline One parent & 87.0 & 14.3 & $1.81(0.84-3.89)$ & 0.128 \\
\hline Both parents & 78.7 & 21.3 & & \\
\hline
\end{tabular}

Overweight/obesity = overweight/obesity $(\mathrm{BAZ}>+1 \mathrm{SD})$. 
Table 4. Overweight/obesity by selected family socio-economic characteristics and residence of the study children.

\begin{tabular}{|c|c|c|c|}
\hline $\begin{array}{l}\text { Socio-demographic } \\
\text { factors }\end{array}$ & $\begin{array}{l}\text { Normal weight } \\
\text { Children (\%) }\end{array}$ & $\begin{array}{l}\text { Overweight/obese } \\
\text { children (\%) }\end{array}$ & p-value \\
\hline \multicolumn{2}{|c|}{ Mother's highest level of education } & & 0.221 \\
\hline University & 79.6 & 20.4 & \\
\hline College & 74.7 & 25.3 & \\
\hline Secondary & 85.3 & 14.3 & \\
\hline \multicolumn{2}{|c|}{ Father's highest level of education } & & 0.058 \\
\hline University & 72.1 & 27.9 & \\
\hline College & 83.7 & 16.3 & \\
\hline Secondary & 86.8 & 13.2 & \\
\hline \multicolumn{2}{|c|}{ Mother's occupation } & & 0.023 \\
\hline Employed & 83.3 & 16.7 & \\
\hline Business & 68.6 & 31.4 & \\
\hline Unemployed & 84.8 & 15.2 & \\
\hline \multicolumn{4}{|c|}{ Father's occupation } \\
\hline Employed & 80.2 & 19.8 & 0.636 \\
\hline Business & 77.4 & 22.6 & \\
\hline \multicolumn{2}{|c|}{ Type of residence } & & 0.028 \\
\hline Apartment & 84.5 & 16.3 & \\
\hline Bungalow & 70.9 & 29.1 & \\
\hline Separated house & 86.8 & 13.1 & \\
\hline Single room & 82.4 & 17.6 & \\
\hline
\end{tabular}

cated by the variations in definitions used by different studies and the different age groups studied [3]. Previous studies among under-fives in Kenya have, however, reported high rates of overweight/obesity in rural and urban areas. Studies in Kenya have reported rates as high as $70 \%$ among female children aged $12-13$ months in rural villages in Western Kenya [12], 18\% among 36 - 59 months [6] and $8 \%-10 \%$ among $5-6$ year olds in rural Kenya [13]. According to the 2008-2009 Kenya Demographic Health Survey [7], the prevalence rate among under-fives was $4.7 \%$ (Weight for height $>+2 \mathrm{SD}$ ). A recent study among school children 9 - 13 years [14] reported a lower prevalence rate of overweight among school children in urban Kenya (16.7\% among girls and $6.8 \%$ among boys) than the current study. Children in the current study were older, a possible reason for the differences. However, when overweight was considered separately, the rates of overweight/obesity were comparable in both studies.

Obesity rates in this study were comparable to rates in some developed countries. These include UK $(5.9 \%$ among girls aged 12 - 14 years [15], Poland, (overweight and obesity rates of $11.8 \%$ and $3.6 \%$, respectively, among 7 - 9 year olds) [16], Greece (17.3\% for overweight and 3.6\% for obesity, among children $6-17$ years) [17], Australia (31.0\% among children aged $4-13$ years)
[18], Canada (32.9\% among girls) [19]. In Iran, the prevalence [20] among urban school girls aged 12 - 17 years was $18.6 \%$ and $5.9 \%$, respectively. Clearly, as a group, urban girls attending private schools in the current study have higher or same rates of overweight/obesity as those in developed countries. When compared to available rates in other urban areas in Africa, which range from $3.4 \%$ in Nigeria to $17 \%$ in South Africa [21-24], obesity rate in the current study was higher. Clearly, overweight/obesity rates in the current study, especially among girls in private schools, is indicative of a public health problem. Just like the current study, other studies have reported higher rates of overweight among girls compared to boys [14,21,23,25-28]. Participation of girls in physical activity may be lower than among boys. In a recent study conducted in Kenya among school children aged 9 - 13 years, girls in urban areas had less aerobic fitness than boys [14]. The same study reported that girls in urban areas completed 26.3 shuttle laps compared with boys who attained 41 laps. Unavailability of public recreation areas within residential areas may contribute to the low activity of children in urban areas. While community playgrounds may not be available close to residential areas, parents may also be more protective of their female children playing in open play grounds, especially when not in school. In addition, differences in dress code between boys and girls in Kenyan schools may also influence the participation of girls in physical activity, as argued by Adamo, et al. [14]. The dresses or skirts worn by girls in most Kenyan schools may be an impediment to participation in physical activity.

In the current study, type of school, mother's occupation, the birth order, having no siblings and type of residence were found to be associated with overweight/obesity. Socioeconomic status has widely been reported to be associated with overweight/obesity in most population groups $[7,9,29,30]$. While in more developed countries overweight/obesity rates are higher among groups with lower socioeconomic status [31-33], most studies in developing countries report the opposite [5,34-36]. In Kenya, past Kenya Demographic surveys (KDHS) and other studies have shown a consistently higher rate of overweight/obesity among women in the higher wealth quartile compared to those in lower quartile $[7,8,30]$.

In the current study, children attending private schools were 3.2 times more likely to be overweight/obese compared to those attending public schools $(29.2 \%$ vs $11.4 \%$ OR $3.295 \%$ CI 1.783, 5.745). While public schools in Kenya are funded by the government through the free primary education programme, private schools charge school fees. It therefore follows that mainly parents who can afford the fees charged opt to enroll their children in private schools. The trend of increasing overweight/obesity with increasing maternal and paternal education levels has been reported in Saudi Arabia [37] and Turkey 
[38]. Higher education levels and employment increase purchasing capacity of households, accompanied by increased calorie availability, especially from fat, high sugar and refined cereal foods. Such families are also able to afford sedentary recreation gadgets and motorised transport. In this study, maternal but not paternal, occupation was associated with overweight/obesity, with the highest rate among children whose mothers were in private business and among those without siblings. Self employed mothers may have a ready and higher flow of disposable income. Overweight/obesity prevalence decreased as the number of siblings increased, and was significantly higher among those without siblings. Similar results were reported among children in Turkey [38], and Portugal [39]. Having fewer siblings implies less sharing of available food (as well as other family resources), and may result in excess energy intake. Children from smaller families may also consume more energy per person compared to children from larger families [27]. Such children may also be getting more attention, implying that the family resources may not be stretched and the child receives the undivided attention of the parents, including gifts, more luxurious foods and more sedentary recreation gadgets and activities. Similarly, last born children may be pampered, probably by having more access to more food, including junk foods, than children in other birth positions as well as being exempted from household chores and other energy expending duties at home. In both cases, the children may engage in less household work and have access to more sedentary recreation gadgets, and hence spend more time in sedentary recreation.

\section{CONCLUSION}

Prevalence of overweight and obesity is high among the study children, posing a public health challenge to nutritionists and policy makers. Being in a private school, having no siblings, the birth order, mother's occupation and the type of residence are positively associated with overweight/obesity.

\section{ACKNOWLEDGEMENTS}

We acknowledge the financial support of the Deutscher Academischer Austausch Dienst (DAAD) and Jomo Kenyatta University of Agriculture and Technology. We are also indebted to the children who willingly participated in the study, the parents who granted consent for participation and school administrations for their support.

\section{REFERENCES}

[1] World Health Organization. (1997) Obesity: Preventing and managing the global epidemic. A report on a WHO consultation on obesity. World Health Organization, Ge- neva, 894, 16-34.

[2] Ebbeling, C.B., Pawlack, D.B. and Ludwig, D.S. (2002) Childhood obesity: Public health crisis, public health cure. Lancet, 360, 473-482. doi:10.1016/S0140-6736(02)09678-2

[3] Lobstein, T., Baur, L. and Uauy, R. (2004) Obesity in children and young people: A crisis in public health. Obesity Reviews, 5, 4-85. doi:10.1111/j.1467-789X.2004.00133.x

[4] De Onis, M. and Blössner, M. (2000) Prevalence and trends of overweight among preschool children in developing countries. American Journal of Clinical Nutrition, 72, 1032-1039.

[5] Martorell, R., Khan, L.K., Hughes, M.L. and Grummer-Strawn, L.M. (2000) Overweight and obesity in preschool children from developing countries. International Journal of Obesity, 24, 959-967. doi:10.1038/sj.ijo.0801264

[6] Gewa, C.A. (2009) Childhood overweight and obesity among Kenyan pre-school children: Association with maternal and early child nutritional factors. Public Health Nutrition, 10, 1-8.

[7] Government of Kenya. (2010) Kenya Health and Demographic Survey, 2008-2009. Government Printer, Nairobi, 143.

[8] Government of Kenya. (2004) Kenya Health and Demographic Survey, 2003. Government Printer, Nairobi, 165.

[9] Li, Y., Zhai, F., Yang, X., Schouten, E.G., Hu, X., He, Y., Luan, D. and Ma, G. Determinants of childhood overweight and obesity in China. British Journal of Nutrition, 97, 210-215. doi:10.1017/S0007114507280559

[10] Gibson, R.S. (2005) Principles of Nutritional Assessments. 2nd Ed. Oxford University Press, Oxford.

[11] WHO (2007). http://www.who.int/growthref/growthrefwhobull/en/index $\underline{\mathrm{html}}$

[12] Abdulkadir, A.E., Sohani, S.A. and Agoi, F. (2009) The dilemma of over- and under-nutrition coexistence among Western Kenya children. AJFAND, 9, 4.

[13] Semproli, S. and Gualdi-Russo, E. (2007) Childhood malnutrition and growth in a rural area of Western Kenya. American Journal of Physical Anthropology, 132, 46. doi:10.1002/ajpa.20470

[14] Adamo, K.B., Sheel, A.W., Onywera, V., Waudo, J., Boit, M. and Tremblay, M.S. (2010) Child obesity and fitness levels among Kenyan and Canadian children from urban and rural environments: A KIDS-CAN research alliance study. International Journal of Pediatric Obesity, 6, e225-e232.

[15] Jebb, S.A., Rennie, K.L. and Cole, T.J. (2003) Prevalence of overweight and obesity among young people in Great Britain. Public Health Nutrition, 7, 461-465.

[16] Małecka-Tendera, E., Klimek, K., Matusik, P., Olszanecka-Glinianowicz, M., Lehingue, Y. and On Behalf of the Polish Childhood Obesity Study Group. (2005) Obesity and overweight prevalence in polish 7- to 9-year-old children. Obesity Research, 13, 964-968. doi:10.1038/oby.2005.112 
[17] Georgiadis, G. and Nassis, G.P. (2007) Prevalence of overweight and obesity in a national representative sample of Greek children and adolescents. European Journal of Clinical Nutrition, 61, 1072-1074. doi:10.1038/sj.ejen.1602619

[18] Waters, E., Ashbolt, R., Gibbs, L., Booth, M., Magarey, A., Gold, L. Kai Lo, S., Gibbons, K., Green, J., O'connor, T., Garrard, J. and Swinburn, B. (2008) Double disadvantage: The influence of ethnicity over socioeconomic position on childhood overweight and obesity: Findings from an inner urban population of primary school children. International Journal of Pediatric Obesity, 3, 196204. doi:10.1080/17477160802141846

[19] Veugelers, P.J. and Fitzgerald, A.L. (2005) Prevalence of and risk factors for childhood overweight and obesity. Canadian Medical Association Journal, 173, 607-613. doi:10.1503/cmaj.050445

[20] Maddah, M. and Nikooyeh, B. (2010) Obesity among iranian adolescent girls: Location of residence and parental obesity. Journal of Health and Population Nutrition, 28, 61-66. doi:10.3329/jhpn.v28i1.4524

[21] Monyeki, K.D, Van Lenthe, F.J. and Steyn, N.P. (1999) Obesity: Does it occur in African Children in a rural community in South Africa? International Journal of Epidemiology, 28, 287-292. doi:10.1093/ije/28.2.287

[22] Ben-Bassey, U.P., Oduwole, A.O. and Ogundipe, O.O. (2007) Prevalence of overweight and obesity in Eti-Osa LGA, Lagos, Nigeria. Obesity Reviews, 8, 475-479. doi:10.1111/j.1467-789X.2007.00408.x

[23] Prista, A., Maia, J.A.R., Damasceno, A. and Beunen, G. (2003) Anthropometric indicators of nutritional status: Implications for fitness, activity, and health in school-age children and adolescents from Maputo, Mozambique. American Journal of Clinical Nutrition, 77, 952-959.

[24] Li, M., Dibley, M.J., Sibbritt, D. and Yan, H. (2006) An assessment of adolescent overweight and obesity in Xi' an City, China. International Journal of Paediatric Obesity, 1, 50-80. doi:10.1080/17477160500538046

[25] Kelishadi, R., Pour, M.H., Sarraf-Zadegan, N., Sadry, G.H., Ansari, R., Alikhassy, H. and Bashardoust, N. (2003) Obesity and associated modifiable environmental factors in Iranian adolescents: Isfahan healthy heart programheart health promotion from childhood. Pediatrics International, 45, 435-442. doi:10.1046/j.1442-200X.2003.01738.x

[26] Jinabhai, C.C., Taylor, M. and Sullivan, K.R. (2003) Implications of the prevalence of stunting, overweight and obesity amongst South African primary school children: A possible nutritional transition? European Journal of Clinical Nutrition, 57, 358-365. doi:10.1038/sj.ejen.1601534

[27] Kruger, R., Kruger, H.S. and MacIntyre, U.E. (2006) The determinants of overweight and obesity among 10- to 15-year-old schoolchildren in the North West Province, South Africa - the THUSA BANA (Transition and Health during Urbanisation of South Africans; BANA, children) study. Public Health Nutrition, 9, 351-358. doi:10.1079/PHN2006849

[28] Ng, S.W., Zaghloul, S., Ali, H.I., Harrison, G. and Popkin, B.M. (2011) The prevalence and trends of overweight, obesity and nutrition-related non-communicable diseases in the Arabian Gulf States. Obesity Reviews, 12, 1-13. doi:10.1111/j.1467-789X.2010.00750.x

[29] Erem, C., Arslan, C., Hacihasanoglu, A., Deger, O., Topbas, M., Ukinc, K., Ersöz, H.O. and Telatar, M. (2004) Prevalence of obesity and associated risk factors in a Turkish population (Trabzon City, Turkey). Obesity Research, 12, 1117-1127. doi:10.1038/oby.2004.140

[30] Steyn, N.P., Nel, J.H., Parker, W., Ayah, R. and Mbithe, D. (2011) Dietary, social, and environmental determinants of obesity in Kenyan women. Scandinavian Journal of Public Health, 39, 88-97. doi:10.1177/1403494810384426

[31] Do Carmo, I., Dos Santos, O., Camolas, J., Vieira, J., Carreira, M., Medina, L., Reis, L., Myatt, J. and Galvão-Teles, A. (2008) Overweight and obesity in Portugal: National prevalence in 2003-2005. Obesity Reviews, 9, 11-19.

[32] Mendez, M.A., Monteiro, C.A. and Popkin, B.M. (2005) Overweight exceeds underweight among women in most developing countries. American Journal of Clinical Nutrition, 81, 714-721.

[33] Faeh, D., Braun, J. and Bopp, M. (2011) Prevalence of obesity in Switzerland 1992-2007: The impact of education, income and occupational class. Obesity Reviews, 12, $1-16$.

[34] Monteiro, C.A., Moura, E.C., Conde, W.L. and Popkin, B.M. (2004) Socio-economic status and obesity in adult populations of developing countries: A review. Bulletin of World Health Organization, 82, 940-946.

[35] Kaneria, Y., Singh, P. and Sharma, D.C. (2006) Prevalence of overweight and obesity in relation to socio-economic conditions in two different groups of school-age children of Udaipur City (Rajasthan). Journal, Indian Academy of Clinical Medicine, 7, 133-135.

[36] Rashidy-Pour, A., Malek, M., Eskandarian, R. and Ghorbani, R. (2009) Obesity in the Iranian population. Obesity Reviews, 10, 2-6. doi:10.1111/j.1467-789X.2008.00536.X

[37] Al-Saeed, W.Y., Al-Dawood, K.M., Bukhari, I.A., and Bahnassy, A. (2006) Prevalence and socioeconomic risk factors of obesity among urban female students in AlKhobar city 2003, Eastern Saudi Arabia. Obesity Reviews, 8, 93-99. doi:10.1111/j.1467-789X.2006.00287.x

[38] Pirinçci, E., Durmus, B., Gündogdu, C. and Açik, Y. (2010) Prevalence and risk factors of overweight and obesity among urban school children in Elazig city, Eastern Turkey, 2007. Annals of Human Biology, JanuaryFebruary, 37, 44-56. doi:10.3109/03014460903218984

[39] Padez', C., Mourao, I., Moreira, P. and Rosado, P. (2005) Prevalence and risk factors for overweight and obesity in Portuguese children. Acta Pediatric, 94, 1550-1555. doi:10.1080/08035250510042924 